Сравнительный анализ динамики показателей качества жизни у больных хронической обструктивной болезнью легких на фоне вакцинации против пневмококковой инфекции с использованием 13-валентной конъюгированной и 23-валентной полисахаридной вакцин

\author{
М.П.Костинов ${ }^{1}$, А.В.Жестков ${ }^{2}$, А.Д.Протасов ${ }^{2}$, Т.А.Костинова ${ }^{1}$, Д.В.Пахомов ${ }^{1}$, А.В. Чебыкина ${ }^{3}$, \\ 0.0. Магаршак $^{1}$
}

1 - ФГБУ "Научно-исследовательский институт вакцин и сывороток им. И.И.Мечникова" РАН: 105064, Москва, Малый Казенный пер., 5А;

2 - ГБОУ ВПО "Самарский государственный медицинский университет" Минздрава России: 443099, Самара, ул. Чапаевская, 89;

3 - Кировское областное ГБУЗ "Кировская городская больница № 9": 610027, Киров, ул. Дерендяева, 97

Резюме

Приводятся сравнительные данные динамики показателей качества жизни (КЖ) у пациентов с хронической обструктивной болезнью легких (ХОБЛ) на фоне вакцинации против пневмококковой инфекции с использованием 13-валентной конъюгированной вакцины "Превенар-13" (ПКВ-13) или 23-валентной полисахаридной вакцины "Пневмо-23" (ППВ-23). Цель: сравнительная оценка влияния вакцинации против пневмококковой инфекции на показатели КЖ у пациентов с ХОБЛ за 12 мес. при использовании ПКВ-13 и ППВ-23. Материалы и методы. В исследовании приняли участие больные ХОБЛ $(n=58)$. Пациенты, соответствующие критериям включения / исключения, в амбулаторных условиях получили внутримышечно в левое плечо 1 дозу вакцины ПКВ-13 (1-я группа; $n=33)$ либо ППВ-23 (2-я группа; $n=25)$. Оценивалась динамика КЖ вакцинированных с использованием COPD Assessment Test (CAT) за 1 год до вакцинации и в течение 1 года после. Результаты. При вакцинации пациентов с ХОБЛ ПКВ-13 отмечено снижение показателей САТ на 10,3 балла; в группе ППВ-23 данный показатель снизился на 8,8 балла $(p<0,05)$. Заключение. Вакцинация больных ХОБЛ против пневмококковой инфекции с использованием ПКВ-13 или ППВ-23 способствует достоверному улучшению показателей КЖ. При наличии выбора введения ПКВ-13 или ППВ-23 у пациентов с ХОБЛ следует отдавать предпочтение в пользу конъюгированного вакцинного препарата. Требуются дополнительные исследования микробиологического, иммунологического и других эффектов при использовании ПКВ-13 и ППВ-23 у пациентов с ХОБЛ, а не только влияние на показатели КЖ.

Ключевые слова: пневмококковая инфекция, вакцинация, хроническая обструктивная болезнь легких, Пневмо-23, Превенар-13, САТ, качество жизни.

DOI: 10.18093/0869-0189-2015-25-2-163-166

\title{
Comparison of quality of life in patients with chronic obstructive pulmonary disease vaccinated with 13-valent conjugate pneumococcal vaccine or 23-valent polysaccharide pneumococcal vaccine
}

\author{
M.P.Kostinov ${ }^{1}$, A.V.Zhestkov ${ }^{2}$, A.D.Protasov ${ }^{2}$, T.A.Kostinova ${ }^{1}$, D.V.Pakhomov ${ }^{1}$, A.V.Chebykina ${ }^{3}$, 0.0.Magarshak ${ }^{1}$ \\ 1 - Federal Institution "I.I.Mechnikov Scientific and Research Vaccine and Serum Institute", Russian Science Academy: 5A, Malyy Kazennyy per., Moscow, 105064, Russia; \\ 2 - State Institution "Samara State Medical University", Healthcare Ministry of Russia: 89, Chapaevskaya str., Samara, 443099, Russia; \\ 3 - Kirov Regional State Healthcare Institution "Kirov city hospital N9": 97, Derendyaeva str., Kirov, 610027, Russia
}

\section{Summary}

\begin{abstract}
The aim of this study was to evaluate an impact of 13-valent conjugate pneumococcal vaccine (PCV-13) and 23-valent polysaccharide pneumococcal vaccine (PPV-23) on quality of life of patients with chronic obstructive pulmonary disease. Methods. We estimated quality of life from baseline to 12 months after the vaccination using the COPD Assessment Test (CAT). Results. The study involved 58 patients with COPD vaccinated with PCV-13 $(n=33)$ or PPV-23 $(n=25)$. The CAT score reduced by 10.3 in patients vaccinated with PCV-13 and by 8.8 in patients vaccinated with PPV-23 $(p<0.05)$. Conclusion. Vaccination of COPD patients with PCV-13 or PPV-23 could significantly improve quality of life. The conjugate vaccine PCV-13 is more preferable. Further studies of microbiological, immunological and other effects of PCV-13 and PPV-23 in COPD patients are needed. Key words: pneumococcal infection, vaccination, chronic obstructive pulmonary disease, PCV-13, PPV-23, CAT-test, quality of life.
\end{abstract}

Хроническая обструктивная болезнь легких (ХОБЛ) является одной из наиболее актуальных проблем современного здравоохранения, в частности пульмонологии. Это связано с высокой распространенностью данного заболевания в мире ( $\approx 64$ млн больных), растущей смертностью (по прогнозам, в течение ближайших 10 лет общая смертность, обусловленная
ХОБЛ, увеличится более чем на 30 \%) и социальноэкономическими затратами [1].

Основными возбудителями инфекционного обострения ХОБЛ являются Streptococcus pneumoniae, Haemophilus influenzae, Moraxella catarrhalis [2, 3], в связи с чем необходимость вакцинации пациентов с ХОБЛ против пневмококковой инфекции не вызывает сомнений. 
Для профилактики пневмококковой инфекции у взрослых в Российской Федерации зарегистрированы 2 вакцинных препарата: 13-валентная конъюгированная вакцина "Превенар-13" (ПКВ-13) и 23-валентная полисахаридная пневмококковая вакцина "Пневмо-23" (ППВ-23).

В клинической медицине существует необходимость разработки и внедрения конъюгированных вакцин против различных инфекций. Однако по опыту показано, что только полисахаридных вакцинных препаратов недостаточно. Принципиальным отличием ПКВ-13 от ППВ-23 является ее конъюгированный характер.

При помощи технологии конъюгирования полисахарида с дифтерийным белком CRM197 обеспечивается принципиально иной механизм действия вакцины. Механизм действия ППВ-23 направлен на активацию В-лимфоцитов с последующим образованием плазматических клеток и синтезом специфических антител. При вакцинации полисахаридными вакцинами, которые являются Т-независимыми антигенами, отсутствует образование клеток памяти, поэтому при повторном введении вакцины отсутствует и должный бустерный эффект.

При конъюгации полисахарида с белком антиген из Т-независимого преобразуется в Т-зависимый, стимулируя ответ Т-хелперов и обеспечивая формирование клеток памяти и иммунологическую реакцию на бустерное введение, что было показано у здоровых добровольцев, но не у пациентов с хронической бронхолегочной патологией [4].

ППВ-23 ("Санофи Пастер", Франция) состоит из очищенных капсулярных полисахаридных антигенов пневмококков 23 серотипов. В каждой дозе содержится по 25 мкг полисахаридного антигена $S$. pneumoniae каждого из 23 серотипов (1-5, 6B, 7F, 8, 9V, 9N, 10A, 11A, 12F, 14, 15B, 17F, 18C, 19A, 19F, 20, 22F, 23F, 33F), консервант - фенол (до 1,25 мг), изотонический буферный раствор (до 0,5 мл).

ПКВ-13 ("Пфайзер", США) представляет собой капсулярные полисахариды 13 серотипов пневмококка (1-5, 6А, 6B, 7F, 9V, 14, 18C, 19A, 19F, 23F), индивидуально конъюгированные с дифтерийным белком CRM197 и адсорбированные на алюминия фосфате. В состав вакцины входит по 2,2 мкг полисахаридов всех перечисленных серотипов, за исключением 4,4 мкг полисахарида серотипа 6В. Указанные полисахариды конъюгированы с $\approx 32$ мкг белка-носителя CRM197. Вспомогательные вещества: алюминия фосфат - 0,5 мг, натрия хлорид $-4,25$ мг, янтарная кислота - 0,295 мг, полисорбат $80-0,1$ мг, вода для инъекций - до 0,5 мл.

Одним из основных показателей эффективности работы системы здравоохранения является качество жизни (КЖ) пациента [5]. КЖ, связанное со здоровьем, рассматривается как один из важнейших показателей эффективности лечения ХОБЛ, т. к. оно коррелирует со снижением легочной функции и затратами на медицинскую помощь. При частых инфекционных обострениях заболевание прогрессирует, соответственно снижается и КЖ.
В предыдущих исследованиях продемонстрирована безопасность и хорошая переносимость ПКВ-13 у пациентов с ХОБЛ [6]. Однако сравнительная оценка влияния вакцинации на показатели КЖ у больных ХОБЛ при использовании ПКВ-13 и ППВ-23 не проводилась.

Целью исследования явилась сравнительная оценка влияния вакцинации против пневмококковой инфекции на показатели КЖ у пациентов с ХОБЛ при использовании ПКВ-13 и ППВ-23 (за 12 мес.).

\section{Материалы и методы}

В открытом одноцентровом проспективном исследовании приняли участие пациенты $(n=58)$ с хронической обструктивной болезнью легких (ХОБЛ), наблюдавшиеся в клиниках ГБОУ ВПО "Самарский государственный медицинский университет" Минздрава России (дата включения 1-го пациента 07.10.12, последнего - 10.05.13). Использовались следующие критерии включения:

- мужчины и женщины в возрасте от 18 лет;

- пациенты с диагнозом ХОБЛ любой степени тяжести, находящиеся вне обострения заболевания (стойкая ремиссия $\geq 4$ нед.);

- пациенты, ранее не получавшие вакцинацию против пневмококка;

- наличие подписанного информированного согласия пациента;

Критериями исключения являлись:

- возраст моложе 18 лет;

- острые инфекционные заболевания, в т. ч. туберкулез;

- активная фаза хронических вирусных гепатитов;

- психические расстройства;

- почечная или печеночная недостаточность;

- злокачественные новообразования;

- хронические заболевания в стадии обострения;

- гиперчувствительность к компонентам вакцины;

- тяжелые осложнения при предшествующих вакцинациях;

- беременность;

- аутоиммунные заболевания;

- вакцинация против пневмококка в анамнезе.

Больные ХОБЛ были рандомизированы подряд сначала в 1-ю, потом во 2-ю группы: 1-я - вакцинированные ПКВ-13 $(n=33)$; 2-я - ППВ-23 $(n=25)$. Объем групп определялся количеством имеющихся вакцин. Исследование в соответствии с протоколом завершили 55 пациентов: 1 пациент из 1-й группы умер при нарастании симптомов хронического легочного сердца; во 2-й группе в 2 случаях отозвано информированное согласие в связи со смертью от прогрессирующей множественной миеломы; данные этих пациентов $(n=3)$ не были включены в анализ (анализ набора данных per protocol). Исходная характеристика и сопоставимость пациентов с ХОБЛ из данных 2 групп по возрасту и тяжести заболевания, объему получаемой бронхолитической и противовоспалительной терапии, а также сопутствующей 
патологии были подробно описаны в работе [7]. На протяжении всего периода исследования базисная терапия ХОБЛ у пациентов обеих групп принципиально не менялась.

Обследуемые никогда раньше не были привиты против пневмококковой инфекции. Заболевание у участников исследования (степень тяжести, клинические особенности, степень функциональных расстройств системы дыхания) диагностировалось в соответствии с GOLD (2011) [8].

У всех пациентов проводился тщательный сбор анамнеза (выявление факторов риска, наличие жалоб на кашель, выделение мокроты, наличие одышки разной степени выраженности, усиливающейся при физической нагрузке). Для верификации диагноза ХОБЛ у всех участников было проведено исследование функции внешнего дыхания и проба с бронхолитическим препаратом (400 мкг сальбутамола) по стандартной методике.

В амбулаторных условиях пациенты получили внутримышечно в левое плечо по 1 дозе ПКВ-13 (ceрия F96122, срок годности до сентября 2014) либо ППВ-23 (серия J0186-5, срок годности до апреля 2014).

Оценка КЖ проводилась в динамике с использованием заполняемой пациентом анкеты из 8 вопросов о симптомах заболевания, а также о своем состоянии (COPD Assessment Test-CAT). Ответ на каждый вопрос оценивался в баллах от 0 до 5, где 0 - самая лучшая характеристика описываемого симптома или состояния, 5 - наихудшее его проявление (чем выше балл, тем хуже КЖ пациента с ХОБЛ, и наоборот). Таким образом, при суммировании результатов САТ оценивается влияние ХОБЛ на КЖ пациента:

- 0-10 баллов - незначительное;

- 11-20 баллов - умеренное;

- 21-30 баллов - сильное;

- $\quad \geq 31$ балла - чрезвычайно сильное.

В данном пилотном исследовании больные ХОБЛ тестировались исходно (до вакцинации) и через 12 мес. В связи с небольшим размером выборки значения САТ приводятся без учета степени тяжести заболевания.

Исследование проводилось в соответствии с этическими нормами и рекомендациями Всемирной организации здравоохранения и Министерства здравоохранения РФ согласно Протоколу от 05.09.12 № 122, утвержденному комитетом по биоэтике ГБОУ ВПО "Самарский государственный медицинский университет" Минздрава России.

Статистическая обработка результатов выполнялась при помощи пакета прикладных программ StatPlus 2009 Professional 5.8.4. Описательные статистики для нормально распределенных величин представлены в виде среднего значения \pm стандартное отклонение (min; медиана; max), а для величин с распределением, отличным от нормального в виде медианы и межквартильного интервала. Статистическая значимость различий оценивалась с использованием теста Уилкоксона, парного двухвыборочного t-теста.

\section{Результаты и обсуждение}

В таблице представлены данные симптомов и состояния в динамике, полученные с помощью САТ у больных ХОБЛ обеих групп исходно и через 12 мес.

При сравнении исходно и через 12 мес. статистически значимых различий между группами не выявлено ( $p>0,05$; тест Манна-Уитни), т. е. группы по анализируемому параметру были сопоставимы исходно, также не отмечалось межгрупповых достоверных различий через 12 мес.

В группе вакцинированных ПКВ-13 средний балл САТ достоверно снизился с 21,8 (сильное влияние ХОБЛ на КЖ пациента) до 11,5 (умеренное влияние), обеспечив падение в 10,3 балла в абсолютных значениях $(p<0,001)$. У пациентов из группы ППВ-23 также отмечалось статистически значимое снижение среднего балла САТ с 22,8 (сильное влияние ХОБЛ на КЖ пациента) до 14 (умеренное влияние; $p<0,001)$. В абсолютных значениях данное снижение составило 8,8 балла.

По результатам пилотного исследования показано, что в случае применения обеих пневмококковых вакцин (полисахаридной и конъюгированной) у больных ХОБЛ достоверно улучшается КЖ, оцененное с помощью САТ. Однако отмечено, что анализируемый параметр улучшается в бо́льшей степени при использовании конъюгированной вакцины по сравнению с полисахаридной пневмококковой вакциной. Результаты данной работы являются дополнительным аргументом в пользу применения ПКВ-13 у больных ХОБЛ при выборе между конъюгированной и полисахаридной вакцинами.

\section{Заключение}

По результатам данного исследования сделаны следующие выводы:

- показатели КЖ у пациентов с ХОБЛ достоверно улучшаются при использовании ПКВ-13 и ППВ23 через 1 год после вакцинации (период наблюдения) по сравнению с исходным показателем;

- через 1 год после вакцинации при использовании ПКВ-13 у больных ХОБЛ средний балл по САТ снижается на 10,3 ( $p<0,001)$, при использовании ППВ-23 - на 8,8 балла $(p<0,001)$;

Таблица

Динамика САТу больных ХОБЛ обеих групп исходно и через 12 мес., баллы

Table

CAT score dynamics in COPD patients of both the groups from baseline to 12 months

\begin{tabular}{l|c|c|}
\multicolumn{1}{|c|}{ САТ } & $\begin{array}{c}1 \text {-я группа, } \\
n=32 \text { (ПКВ-13) }\end{array}$ & $\begin{array}{c}\text { 2-я группа, } \\
n=23 \text { (ППВ-23) }\end{array}$ \\
\hline $\begin{array}{l}\text { Исходно } \\
\text { Через } 12 \text { мес. }\end{array}$ & $21,8 \pm 10,3(3 ; 20,5 ; 38)$ & $22,8 \pm 9,9(2 ; 25 ; 37)$ \\
$\begin{array}{l}\text { Изменение среднего } \\
\text { балла от исходного } \\
\text { значения }\end{array}$ & $-11,5(7 ; 24)$ & $14(0 ; 14 ; 33)$ \\
\hline
\end{tabular}

Примечание: * - p<0,001 - при сравнении показателя исходно и через 12 мес. в соответствующей группе 
- с целью улучшения КЖ при наличии выбора введения ПКВ-13 или ППВ-23 у пациентов с ХОБЛ следует отдавать предпочтение в пользу конъюгированного вакцинного препарата.

\section{Литература}

1. World Health Organization. Chronic obstructive pulmonary disease. 2012. Available at: http://www.who.int/mediacentre/factsheets/fs315/en/index.html

2. Протасов А.Д. Иммунологический и клинический эффекты сочетанного применения вакцин против пневмококковой, гемофильной типа b инфекций и гриппа у больных с хронической обструктивной болезнью легких: Автореф. дис. ... канд. мед. наук. М.; 2012.

3. Протасов А.Д., Жестков А.В., Лаврентьева Н.Е. и др. Эффект комплексной вакцинации против пневмококковой, гемофильной типа b инфекций и гриппа у пациентов с хронической обструктивной болезнью легких. Журнал микробиологии, эпидемиологии и иммунобиологии. 2011; 4: 80-84.

4. Перова А.Л., Рулева А.А. Вакцинация против пневмококковой инфекции. Лечение и профилактика. 2013; 4 (8): 43-53.

5. Сенкевич Н.Ю., Ханова Ф.М., Сафрыгин К.В. Четыре вопроса о качестве жизни. Атмосфера. Пульмонология и аллергология. 2002; 4: 26-28.

6. Протасов А.Д., Жестков А.В., Костинов М.П. Первые результаты применения 13-валентной конъюгированной пневмококковой вакцины у больных хронической бронхолегочной патологией: оценка безопасности и переносимости. Российский аллергологический журнал. 2013; 4: 18-23.

7. Протасов А.Д. Сравнительная оценка эффективности вакцинации против пневмококковой инфекции у пациентов с хронической обструктивной болезнью легких при использовании 13-валентной конъюгированной и 23-валентной полисахаридной вакцин. Российский аллергологический журнал. 2014; 4: 12-17.

8. Белевский А.С., ред. Глобальная стратегия диагностики, лечения и профилактики хронической обструктивной болезни легких (пересмотр 2011 г.). М.: Российское респираторное общество; 2012.

Поступила 22.12.14 удк 616.24-036.12-085.371

\section{References}

1. World Health Organization. Chronic obstructive pulmonary disease. 2012. Available at: http://www.who.int/mediacentre/ factsheets/fs315/en/index.html

2. Protasov A.D. Immune and clinical effects of combined vaccination against pneumococcus, type B Haemophilus and influenza infections: Diss. Moscow; 2012 (in Russian).

3. Protasov A.D., Zhestkov A.V., Lavrent'eva N.E. et al. Effects of combined vaccination against pneumococcus, type B Haemophilus and influenza infections in patients with chronic obstructive pulmonary disease. Zhurnal mikrobiologii, epidemiologii i immunobiologii. 2011; 4: 80-84 (in Russian).

4. Perova A.L., Ruleva A.A. Vaccination against pneumococcus infection. Lechenie i profilaktika. 2013; 4 (8): 43-53 (in Russian)

5. Senkevich N.Yu., Khanova F.M., Safrygin K.V. Four questions about quality of life. Atmosfera. Pul'monologiya i allergologiya. 2002; 4: 26-28 (in Russian).
6. Protasov A.D., Zhestkov A.V., Kostinov M.P. The first experience of vaccination with 13-valent conjugate vaccine against pneumococcus in patients with chronic bronchopulmonary disease: safety and efficacy. Rossiyskiy allergologicheskiy zhurnal. 2013; 4: 18-23 (in Russian).

7. Protasov A.D. A comparative assessment of efficacy of 13valent conjugate vaccine and 23 -valent polysaccharide vaccine against pneumococcus in patients with chronic obstructive pulmonary disease. Rossiyskiy allergologicheskiy zhurnal. 2014; 4: 12-17 (in Russian).

8. Belevskiy A.S.,ed. Global Strategy for Diagnosis, Management, and Prevention of chronic obstructive pulmonary disease. Updated 2011. Moscow: Rossiyskoe respiratornoe obshchestvo; 2012 (in Russian).

Received Dec 22, 2014

UDC 616.24-036.12-085.371

\section{Информация об авторах}

Костинов Михаил Петрович - д. м. н., профессор, зав. лабораторией вакцинопрофилактики и иммунотерапии аллергических заболеваний ФГБУ "НИИВС им. И.И.Мечникова" РАН; тел. / Факс: (495) 917-41-49; e-mail: vaccine@bk.ru

Жестков Александр Викторович - д. м. н., профессор, зав. кафедрой общей и клинической микробиологии, иммунологии и аллергологии ГБОУ ВПО "Самарский государственный медицинский университет" Минздрава России; тел. / факс: (846) 260-33-61; e-mail: zhestkovav @yandex.ru

Протасов Андрей Дмитриевич - к. м. н., ассистент кафедры общей и клинической микробиологии, иммунологии и аллергологии ГБОУ ВПО "Самарский государственный медицинский университет" Минздрава России; тел. / факс: (846) 260-33-61; e-mail: crosss82@mail.ru Костинова Татьяна Алексеевна - врач аллерголог-иммунолог лаборатории вакцинопрофилактики и иммунотерапии аллергических заболеваний ФГБУ "НИИ вакцин и сывороток им. И.И.Мечникова" РАН; тел. (495) 917-41-49; e-mail: kostinova@rambler.ru

Пахомов Дмитрий Владимирович - к. м. н., ст. научный сотрудник лаборатории вакцинопрофилактики и иммунотерапии аллергических заболеваний ФГБУ "НИИ вакцин и сывороток им. И.И.Мечникова" РАН тел.: (495) 917-41-49; e-mail: dm_pachomov@mail.ru

Чебыкина Анна Владимировна - К. м. н., зав. пульмонологическим отделением КО ГБУЗ "Кировская городская больница № 9"; (905) 870-37-25; e-mail: annmed@list.ru

Магаршак Ольга Олеговна - к. м. н., ст. научный сотрудник лаборатории вакцинопрофилактики и иммунотерапии аллергических заболеваний ФГБУ "НИИ вакцин и сывороток им. И.И.Мечникова" РАН; тел. (495) 917-41-49; e-mail: vaccine@bk.ru

\section{Author information}

Kostinov Mikhail Petrovich, MD, Professor, Head of Laboratory of Vaccine Prevention and Immune Therapy of Allergic Diseases, Federal Institution "I.I.Mechnikov Scientific and Research Vaccine and Serum Institute", Healthcare Ministry of Russia; tel. / fax: (495) 917-41-49; e-mail: vaccine @bk.ru

Zhestkov Aleksandr Viktorovich, MD, Professor, Head of Department of General and Clinical Microbiology, Immunology and Allergology, State Institution "Samara State Medical University", Healthcare Ministry of Russia; tel. / fax: (846) 260-33-61; e-mail: zhestkovav@yandex.ru Protasov Andrey Dmitrievich, PhD, Assistant at the Department of Genera and Clinical Microbiology, Immunology and Allergology, State Institution "Samara State Medical University", Healthcare Ministry of Russia; tel. / fax: (846) 260-33-61; e-mail: crosss82@mail.ru

Kostinova Tat'yana Alekseevna, an allergist and immunologist, Laboratory of Vaccine Prevention and Immune Therapy of Allergic Diseases, Federa Institution "I.I.Mechnikov Scientific and Research Vaccine and Serum Institute", Russian Science Academy; tel.: (495) 917-41-49; e-mail: kostinova @rambler.ru

Pakhomov Dmitriy Vladimirovich, PhD, Senior Researcher, Laboratory of Vaccine Prevention and Immune Therapy of Allergic Diseases, Federal Institution "I.I.Mechnikov Scientific and Research Vaccine and Serum Institute", Russian Science Academy; tel.: (495) 917-41-49; e-mail: dm pachomov @mail.ru

Chebykina Anna Vladimirovna, PhD, Chief Pneumologist, Kirov Regional State Healthcare Institution "Kirov city hospital N9"; tel.: (905) 870-37-25; e-mail: annmed@list.ru

Magarshak Ol'ga Olegovna, PhD, Senior Researcher, Laboratory of Vaccine Prevention and Immune Therapy of Allergic Diseases, Federal Institution "I.I.Mechnikov Scientific and Research Vaccine and Serum Institute", Russian Science Academy; tel.: (495) 917-41-49; e-mail: vaccine@bk.ru 